\title{
DISPENSÁRIO DE PUERICULTURA DA ESCOLA PROFISSIONAL FEMININA: REFLEXÕES SOBRE HISTÓRIAS DE VIDA E CULTURA ESCOLAR ${ }^{1}$
}

\author{
Maria Lucia Mendes de Carvalho \\ Centro Paula Souza/ GEPEMHEP \\ maria.mendes@cps.sp.gov.br
}

\begin{abstract}
RESUMO
A primeira Escola Profissional Feminina da capital de São Paulo teve a primazia de estabelecer um Dispensário de Puericultura, devido à estratégia adotada pelo diretor daquela escola, de promover as práticas escolares na cadeira de "Economia doméstica e puericultura". Uma análise da historicidade dos documentos do Centro de Memória daquela escola, entre 1931 e 1975, permitiu identificar por meio da cultura escolar como as práticas pedagógicas e escolares foram empregadas para formação da mulher. Como tática para divulgar as práticas escolares naquele Dispensário de Puericultura, as mães e suas crianças participavam dos Concursos de Robustez que eram amplamente divulgados pela imprensa.
\end{abstract}

Palavras-chave: Educação profissional. Dispensário de puericultura. Cultura escolar. Alimentação. Nutrição.

\section{CHILD CARE'S DISPENSARY IN THE WOMEN PROFISSIONAL SCHOOL: REFLECTIONS ON STORIES OF LIFE AND SCHOOL CULTURE}

\begin{abstract}
The first Women Professional School in the capital of São Paulo had the primacy of establishing a Dispensary of Child Care, due to strategy adopted by the director of that school, to promote the school practices in the chair, "Home economics and child care". An analysis of the historical documents of the Centre of Memory of that school, between 1931 and 1975, identified through the school culture as teaching and school practices were used for women's training. As a tactic to divulge the practices of that Dispensary of Child Care, mothers and their children participated in Contests Robustness, which were published by the press.
\end{abstract}

Keywords: Professional education. Dispensary of child care. School culture. Food. Nutrition.

\section{DISPENSADOR DE PUERICULTURA DE LA ESCUELA PROFESIONAL FEMENINA: REFLEXIONES SOBRE HISTORIAS DE VIDA Y CULTURA ESCOLAR}

\section{RESUMEN}

La primera Escuela Profesional Femenina de la capital de São Paulo tuvo la primacia de establecer un Dispensario de Puericultura, debido a la estrategia adoptada por el director de esa escuela, de promover las prácticas escolares en la silla de "Economia doméstica y puericultura". Un análisis de la historicidad de los documentos del Centro de Memoria de esa escuela, entre 1931 y 1975, permitió identificar por medio de la cultura escolar cómo las prácticas

\footnotetext{
${ }^{1}$ Uma versão desse trabalho foi apresentada no III Seminário de Educação - Memórias, Histórias e Formação de Professores, na Universidade do Estado do Rio de Janeiro, São Gonçalo/RJ, em setembro de 2007.
} 
pedagógicas y escolares fueron empleadas para la formación de la mujer. Como táctica para divulgar las prácticas escolares en ese Dispensario de Puericultura, las madres y sus niños participaban en los Concursos de Robustez que eran ampliamente divulgados por la prensa.

Palabras clave: Educación profesional. Dispensario de puericultura. Cultura escolar. Alimentación. Nutrición.

\section{DISPENSAIRE DE PUÉRICULTURE DE L'ECOLE FÉMININE PROFESSIONNELLE: RÉFLEXIONS SUR DES HISTOIRES DE VIE ET LA CULTURE SCOLAIRE}

\section{RÉSUMÉ}

La première École Féminine Professionnelle dans La capitale de São Paulo a été la primauré de la création d'um Dispensaire de Puériculture, en raison de l'estratégie adoptée par le directeur de cette école, en vue de promouvoir des scolaires pratiques, sous la discipline, "L'Économie domestique et puériculture". Une analyse des documents historiques du Centre de la Mémoire de cette école, entre 1931 et 1975, a permis l'identification Grace à la culture scolaire comme des pratiques scolaires et d'enseignement lesquelles ont été utilisés pour la formaton des femmes. Comme une tactique pour diffuser lês pratiques de celle Dispensarie de Puériculture, lês mères et leurs enfants ont participé au Concours de Robustesse qui ont été divulguées par la presse.

Mots-clés: Éducation professionnel. Dispensarie de puériculture. Culture scolaire. Alimentation. Nutrition.

\section{INTRODUÇÃO}

Este artigo analisa as estratégias e as táticas adotadas no Dispensário de Puericultura da primeira Escola Profissional Feminina da cidade de São Paulo, para preparar meninas e adolescentes para a vida do lar, qualificando-as para a "Educação Doméstica" ou para a formação de "Mestres para o Ensino Profissional e Doméstico", com ênfase na puericultura e na cultura escolar.

O Dispensário de Puericultura, daquela escola, foi criado em outubro de 1931, pelo seu diretor Horácio Augusto da Silveira que, em 1934, assumiu a Superintendência do Ensino Profissional $^{2}$. Desde 2001 aquele Dispensário é objeto da nossa pesquisa e a sua origem devese ao artigo publicado de Maria Alice Rosa Ribeiro, que diz "quase nada encontrou sobre o

\footnotetext{
${ }^{2}$ Entre 1911 e 1934, o ensino profissional permaneceu subordinado à Diretoria-Geral da Instrução Pública, órgão da Secretaria do Interior do Estado de São Paulo até 1931, quando é então criada a Secretaria da Educação e Saúde do Estado. Em 1934 organiza-se uma nova instância, diretamente vinculada ao Secretário da Educação e exclusivamente destinada à administração do ensino profissional: a Superintendência da Educação Profissional e Doméstica (decreto $n^{\circ} .6604$ de 13/8/1934). Até essa época, a coordenação do ensino profissional foi exercida pelo diretor da Escola Masculina da Capital, o professor normalista Aprígio Gonzaga, cargo que exerceu, portanto, durante vinte e três anos. (MORAES, 2003, p. 405).
} 
Dispensário de Puericultura, ao consultar fontes oficiais, como os relatórios da Secretaria do Interior, da Secretaria da Educação e Saúde Pública, dos diretores das escolas"3 e, por dispormos no Centro de Memória da Escola Técnica Estadual Carlos de Campos, atual denominação da Escola Profissional Feminina, que pertence à rede de escolas técnicas do Centro Paula Souza, um acervo documental textual e iconográfico repleto de informações valiosas sobre o dispensário de puericultura daquela escola, no bairro do Brás, na cidade de São Paulo (CARVALHO, 2006).

Tendo como objeto da pesquisa aquele Dispensário de Puericultura, estabelecido para tratar gratuitamente as crianças da comunidade do entorno da escola e, por finalidade, considerar o espaço, o tempo e a subjetividade dos seus integrantes, propusemos-nos a "refletir acerca da relação entre a prática da pesquisa de campo e da produção do discurso historiográfico" (CERTEAU, 1982 apud VIDAL, 2005, p. 22).

Horácio Augusto da Silveira, quando apresentou no $2^{\circ}$ Congresso Feminista, em São Paulo, em 1931, um plano de estudo para a cadeira de "Puericultura", propondo a criação de um centro de puericultura, ao lado daquela Escola, o fez de forma estratégica ${ }^{4}$, considerando as possibilidades de atender as crianças pobres do bairro, fornecer receitas médicas e de alimentação dietética às mães e oferecer aulas práticas às alunas dos cursos de Educação Doméstica (SILVEIRA, 1931). Desde a fundação daquela Escola, em 1911, as alunas recebiam formação de verdadeiras donas de casa na cadeira de "Economia Doméstica e Puericultura", faltando-lhes as aulas práticas, que poderiam ser realizadas com a criação de um Dispensário de Puericultura.

Em outubro de 1931, a cadeira de Puericultura ${ }^{5}$ ganha relevância no curso de formação de "Mestres para o Ensino Profissional e Doméstico", quando as alunas passam a ter aulas

\footnotetext{
${ }^{3}$ RIBEIRO, Maria Alice Rosa. Qualificação da Força de Trabalho: a experiência das Escolas Profissionais do Estado de São Paulo (1911 - 1942). Acervo da Profa. Carmem Sylvia Vidigal Moraes. Centro de Memória da Faculdade de Educação da Universidade de São Paulo. Acesso em: 31 out. 2001.

${ }^{4}$.Chama de estratégia o cálculo (ou a manipulação) das relações de forças que se torna possível a partir do momento em que um sujeito de querer e poder pode ser isolado. A estratégia postula um lugar suscetível de ser circunscrito como algo próprio e ser a base de onde se podem gerir as relações de uma exterioridade de alvos e ameaças [...] gesto da modernidade científica [...] o "próprio" é uma vitória do lugar sobre o tempo. (CERTEAU, 1994, p. 99).

${ }^{5}$ Maria Antonieta de Castro apresentou muitos trabalhos em congressos e conferências, clamando pela inclusão da disciplina Puericultura nos programas escolares, pois desde 1916, o prof. José Escobar, em carta dirigida ao então Secretário do Interior, chamava a atenção para esta inclusão. Ela informa que o ensino de puericultura, que, em 1918, fora introduzido, por Oscar Thompson, nos programas dos quartos anos da escola primária, dele foi retirado em 1925. Desde então, somente em 1926, Maria Antonieta conseguiu organizar na Inspetoria de Educação Sanitária, o primeiro curso regular de puericultura, no Centro Modelo, e segundo ela: "apesar dos obstáculos oriundos da má vontade e da má compreensão de sua finalidade, quiçá dentro do próprio serviço". Este curso era destinado as alunas das classes adiantadas dos grupos escolares "Prudente de Morais" e "Regente Feijó", contando a adesão de senhoras e senhoritas da sociedade e alunas da escola normal. As atividades desenvolvidas
} 
teóricas e práticas, no recém-criado Dispensário de Puericultura daquela escola. A Figura 1 mostra o médico pediatra Dr. Jorge Morais de Barros $^{6}$ examinando uma criancinha e fazendo prelação às alunas, na década de 30 , naquele Dispensário.

Naquela década a mortalidade infantil mobilizava os educadores em prol do ensino da puericultura (CARVALHO, 2006). Na tese "O Ensino da Puericultura nas Escolas e Agremiações Femininas", que Maria Antonieta de Castro, apresentou na Conferência Nacional de Proteção à Infância, em setembro de 1933, está indicado de forma clara à necessidade de envolver a sociedade em defesa da criança (CASTRO, 1933):

[...] O interesse pelos problemas de assistência e proteção à infância vai se implantando, cada vez mais, na consciência coletiva. Sob o influxo das idéias renovadoras, as sombras do passado começam a dissipar-se ante a luz de novas auroras que fazem, de cada homem - o defensor dos direitos fundamentais da criança e, de cada lar - o baluarte da redenção da infância, que, de outro modo, entregue a si mesma, não seria capaz de defender-se, desertando cedo e, tragicamente, da vida. [...]

Figura 1 - Dispensário de Puericultura do Instituto Profissional Feminino da Capital. O médico pediatra Dr. Jorge Morais de Barros examinando uma criancinha e fazendo prelação às alunas, década de 30.

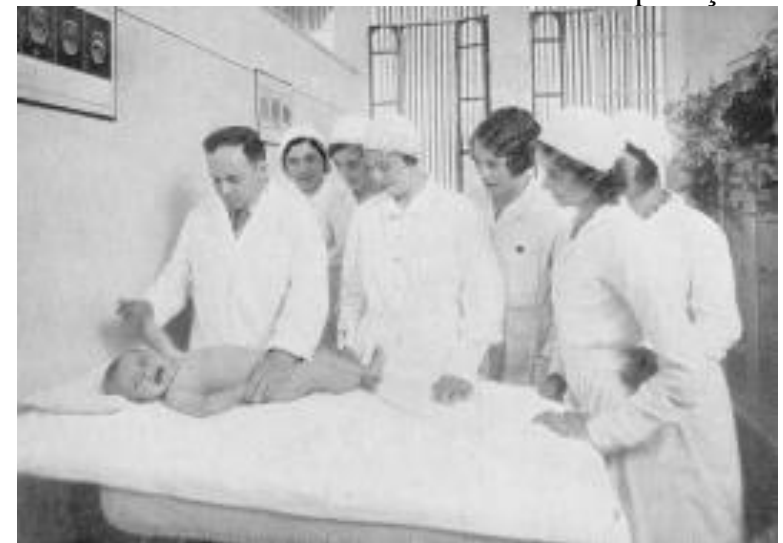

Fonte: Acervo do Centro de Memória da Etec Carlos de Campos, em 2002.

Maria Antonieta de Castro, educadora sanitarista, em 1933, considerava que a miséria e a ignorância eram as grandes aliadas da mortalidade infantil, em todas as camadas sociais brasileira, declarando que "[...] preparar, pois, a mulher, para a arte de bem criar os filhos, é uma necessidade que ninguém mais contesta". Naquela tese, ela diz que a escola constitui o aparelhamento ideal para a divulgação da Puericultura, podendo tal ensino se estender desde os últimos graus da escola primária até as normais, profissionais, domésticas, etc.; e considera que os Dispensários Infantis, Escola Popular de Puericultura, se bem orientadas as suas atividades, poderão abranger serviços de higiene infantil, pré-natal, e não raro, o lactário, dizendo que:

nos serviços de higiene infantil e do lactário, propiciavam um verdadeiro laboratório de dietética infantil, permitindo um curso prático com demonstrações sobre pesagem, banho, preparo de leites, etc. (CASTRO, 1933). ${ }^{6}$ Instituto Profissional Feminino. Relatórios dos Trabalhos Escolares em 1937, São Paulo. 
[...] contam com uma concorrência numerosa e obrigatória das mães que aí podem adquirir uma grande soma de conhecimentos, principalmente, depois que FINKBLSTEIN, MEYER e outros elaboraram princípios de tão grande valor em matéria de alimentação infantil, e pediatras de nome, dia a dia acumulam novos e úteis conhecimentos [...].

Horácio Augusto da Silveira, sujeito moderno ${ }^{7}$, e atento às necessidades de sua época, no que diz respeito ao problema da alimentação coletiva, inaugura em 17 de Maio de 1939, novamente de forma estratégica, o "Curso de Dietética para Donas de Casa", ao mesmo tempo o médico-chefe Francisco Pompêo do Amaral organiza o primeiro curso de dietética profissional existente no Brasil, destinado a formação de "Auxiliares de Alimentação" (SÃO PAULO, 1939).

Naquele ano, a Superintendência do Ensino Profissional já tinha implantado no Estado de São Paulo sete Dispensários de Puericultura nas escolas profissionais de: Campinas, Mococa, São Carlos, Sorocaba, Limeira, Ribeirão Preto e de Santos. Naqueles Dispensários para as Escolas Profissionais Secundárias Mistas do Interior e para a Escola Profissional Secundária do Instituto Profissional Feminino da Capital $\left(1^{\circ}\right.$ grau $)$ as aulas práticas da cadeira de "Puericultura" eram ministradas por uma educadora sanitária nos cursos de "Educação doméstica e dietética para donas de casa". Enquanto que, no curso de aperfeiçoamento do Instituto Profissional Feminino da Capital ( $2^{\circ}$ grau) para formação de "Mestres de Educação Profissional e Auxiliares em Alimentação", as aulas teóricas e práticas da cadeira de Puericultura eram ministradas pelo médico e pela educadora sanitarista do Dispensário de Puericultura.

Para a implantação dos novos currículos para os cursos de Educação Doméstica, nas escolas profissionais da capital e do interior do Estado de São Paulo, a Superintendência do Ensino Profissional organizou o livro institucional "Os Cursos de Dietética", fomentando os programas da cadeira de Puericultura para o ensino de primeiro e segundo graus e indicando as práticas pedagógicas referentes às aulas teóricas e práticas daquela cadeira. (SÃO PAULO, 1939).

\footnotetext{
7 "Para Foucault, o sujeito moderno não está na origem dos saberes; ele não é o produto de saberes mas, ao contrário, ele é um produto dos saberes. Ou, talvez melhor, o sujeito não é um produtor, mas é produzido no interior de saberes" (VEIGA-NETO, 2003).
} 
Os Concursos de Robustez ${ }^{8}$, promovidos pela imprensa todos os anos, poderiam ser considerados como táticas ${ }^{9}$ para divulgar as práticas escolares desenvolvidas pelas alunas das escolas profissionais no campo da puericultura, orientadas por educadoras sanitaristas e médicos pediatras e higienistas. A Figura 2 mostra as mães com suas crianças participando daquele concurso no Dispensário de Puericultura do Instituto Profissional Feminino da Capital, na década de $30 .{ }^{10}$ Durante a gestão administrativa da diretora Laia Pereira Bueno, de 1937 a 1951, naquela escola, as estratégias fomentadas por Horácio Augusto da Silveira foram mantidas e desenvolvidas. No entanto, em 1950, aconteceu um evento que modificou as práticas escolares que até então eram realizadas naquele Dispensário na cadeira de Puericultura. Neste momento nos propusemos a investigar:

Quais as resistências operadas e as apropriações efetuadas pelos diversos sujeitos escolares das imposições do espaço nas instâncias do tempo? E o que essa luta os revela acerca dos vários significados sociais da escola e acerca das práticas escolares? (VIDAL, 2005, p. 64).

Neste artigo incluímos depoimentos de ex-alunas, ex-professoras e ex-professores, que atuaram naquele Dispensário ou ministraram a disciplina Puericultura naquela escola, colhidos nas entrevistas de história oral que realizamos em pesquisa anterior (CARVALHO; RIDOLFI, 2002; CARVALHO; FERREIRA, 2001). Esses relatórios de pesquisas elaborados para o projeto "Historiografia das Escolas Técnicas mais Antigas do Estado de São Paulo" realizado em parceria com o Centro de Memória da Faculdade de Educação da Universidade de São Paulo e o Centro Estadual de Educação Tecnológica Paula Souza e, com apoio da Fundação de Amparo a Pesquisa do Estado de São Paulo, nestes relatórios estão os documentos textuais, iconográficos e tridimensionais empregados nesta pesquisa, e que encontram-se localizados no acervo do Centro de Memória daquela Escola.

\footnotetext{
${ }^{8}$ Escola Profissional Feminina. Álbum de Recortes. Acervo do Centro de Memória da Escola Técnica Estadual Carlos de Campos. Disponível em: http://www.cpscetec.com.br/memorias/livros/carloscampos/albumderecortes.pdf

${ }^{9}$ Para Certeau (1994, p. 98), “a força desses cálculos (estatísticos) se deve à capacidade de dividir, mas essa capacidade analítica suprime a possibilidade de representar trajetórias táticas que, segundo critérios próprios, selecionam fragmentos tomados nos vastos conjuntos da produção para a partir deles compor histórias originais. Contabiliza-se aquilo que é usado, não as maneiras de utilizá-los. Paradoxalmente, estas se tornam invisíveis no universo da codificação e da transparência generalizadas. Dessas águas que se vão insinuando em toda a parte só se tornam perceptíveis os efeitos (a quantidade e a localização dos produtos consumidos). Elas circundam sem ser vistas, perceptíveis somente por causa dos objetos que movimentam e fazem desaparecer. As práticas de consumo são os fantasmas da sociedade que leva o seu nome. Como os "espíritos" antigos, constituem o postulado multiforme e oculto da atividade produtora."

${ }^{10}$ Instituto Profissional Feminino. Relatório dos Trabalhos Escolares em 1938, São Paulo.
} 
Figura 2 - Concurso de robustez infantil no Dispensário de Puericultura do Instituto Profissional Feminino da Capital, atual ETE Carlos de Campos, década de 30.

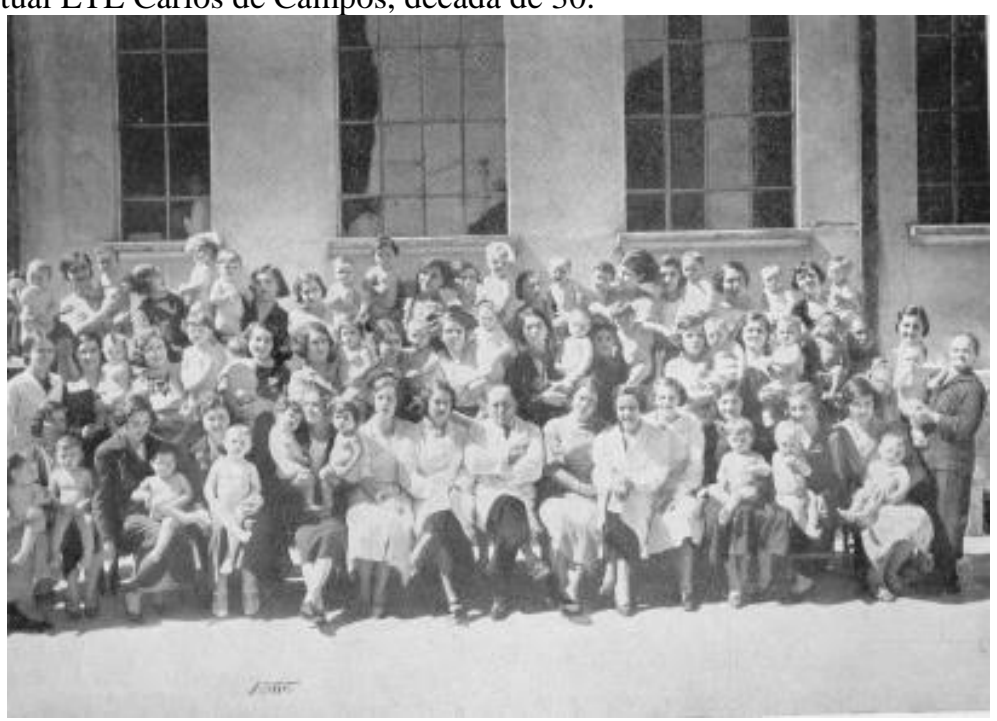

Fonte: Acervo do Centro de Memória da Etec Carlos de Campos, em 2002.

Os instrumentos metodológicos empregados para o delineamento da pesquisa foram: a coleta, a seleção e a análise dos dados obtidos em documentos textuais e iconográficos (BARDIN, 2004). Como referencial teórico para apropriação da categoria cultura escolar neste estudo historiográfico dos instrumentos de ensino-aprendizagem empregados na cadeira de Puericultura daquele Dispensário para qualificar profissionais femininas, utilizamos as definições propostas pelos historiadores - Azanha, Certeau, Gvirtz, Julia, Vidal, Viñao Frago e, a partir destas informações e conhecimentos, iniciamos uma reflexão sobre a influência da cultura escolar na aprendizagem da puericultura, na organização pedagógica racional e nas representações sociais, em relação à escola (ROCHA, 2000), desenvolvida naquele estabelecimento por profissionais sanitaristas.

Para compreender os significados das mudanças que ocorreram na cadeira de Puericultura $^{11}$, com o ingresso do médico Henrique Grechi, por concurso público, naquela Escola, em 1950, as professoras Eliana Roda Ferreira, Maria Lucia Mendes de Carvalho e Suely Teresa de Oliveira entrevistaram, em 20 de dezembro de 2001, em sua residência, este médico, buscando indícios das práticas escolares naquele Dispensário de Puericultura. Segundo o Dr. Grechi:

[...] O Dispensário era aberto ao público, atendia puericultura, praticamente não era pediatria, era mais puericultura, quer dizer medicina preventiva. Uma medicina para evitar que a criança fique doente, era isso que era feito. Os cuidados de prevenção.

\footnotetext{
${ }^{11}$ Para Viñao Frago (1995, p. 66), "la historia de las disciplinas, su gênesis y configuración como tales, com um caráter autônomo, no puede pues hacerse sin analizar la formación, las credenciales y el proceso de selección de quienes a ella se dedican o pretenden hacerlo".
} 
Alias a minha cadeira também, embora eu fosse pediatra, a minha cadeira só se ensinava como defender a criança ou prevenir moléstias da criança. Nós não tratávamos de doenças na infância, fazíamos só a parte de prevenção e higiene. $O$ Dispensário, justamente quando eu entrei na Carlos de Campos, por concurso, eu tinha mais três colegas, estava o Laurindo que ficou com a cadeira de higiene industrial, as duas cadeiras que foram criadas na Carlos de Campos, em 1953, por concurso, eu entrei em 1950. Em 53 tinha uma lei 2318, de 9 de outubro de 1953, foram criadas as cadeiras de Puericultura nos seguintes cursos Formação de Mestres de Economia Domestica e Trabalhos Manuais e no curso de Formação de Dietistas, seria Técnico em Nutrição [...].

O Dr. Henrique Grechi cita, naquela entrevista concedida, a Lei $\mathrm{n}^{\circ} 2.318$, de 9 de dezembro de 1953, por que esta modificou o Decreto estadual $n^{\circ} .10 .033$, de 03 de março de 1939, que fundou o curso de formação de "Mestres de Educação Doméstica e Auxiliares de Alimentação", desdobrando aquele curso em dois cursos distintos: curso de "Formação de Profissionais de Educação Doméstica e Artes Manuais" e curso de "Formação de Dietistas". Este último curso foi regulamentado pelo ato $\mathrm{n}^{\circ} 4$ de 03 de dezembro de 1954 pela Secretaria da Educação ${ }^{12}$. No seu depoimento para o Centro de Memória da Escola Técnica Estadual Carlos de Campos foi possível elucidar quando exatamente ocorreram as mudanças nas práticas escolares referentes às aulas teóricas e práticas da cadeira de "Puericultura" nos cursos ministrados naquela Escola.

[...] Quando o Dr. Moraes Barros se aposentou ou faleceu, não sei exatamente, porque ele saiu da escola, a cadeira ficou vaga, ele era o titular da cadeira, o médico do dispensário, ele dava as aulas teóricas e depois dava as aulas praticas no dispensário. Eu não sei se ele era médico do serviço sanitário ou do Estado, o dispensário estava todo equipado para atender perfeitamente o público. Quando ele saiu, naquele tempo a gente não se aposentava, falecia, ele deixou vago o dispensário. Quem ficou no lugar dele, era um assistente dele, chamado Mario Taddeo. O Dr. Mario Taddeo ficou no dispensário atendendo as crianças. Dava as aulas teóricas também. Acontece que aquela era uma disciplina da escola. Como ficou vago, então foi aberto um concurso, é nessa hora que eu entrei. Fui avisado seis meses antes pela D. Dirce, que era conhecida nossa, ela falou: - vai abrir uma vaga lá de Puericultura, você se inscreve, se prepara. Eu peguei o programa estudei, eu nem fazia pediatria, eu era médico clinico geral. Então eu gosto muito de magistério, metade da minha vida é magistério. Então eu comecei estudar Puericultura e consegui primeiro lugar no concurso, o Taddeo ficou em segundo. O que acontece, o Taddeo tinha então que sair, tinha que me entregar o que, tinha que me entregar as aulas teóricas e tinha que me entregar o dispensário, para continuar o que o Moraes Barros estava fazendo, acontece que o Taddeo era médico do Estado, tava locado no dispensário, então eu acho que houve ali um acerto para que ele não fosse para a rua e continuasse trabalhando lá, então o dispensário ficou com ele e eu fiquei só com aulas teóricas. A partir desse dia que o dispensário ficou para ele (Taddeo) é como se o dispensário não pertencesse mais a escola Carlos de Campos A partir desse dia que o dispensário ficou para ele e eu com

12 Citado no trabalho de alunas apresentado no Colégio Estadual de Artes Aplicadas e Economia Doméstica "Carlos de Campos", na disciplina'"Comunicação e Educação Alimentar, sob a orientação da Prof Neide $^{\mathrm{a}}$ Gaudenci de Sá, pelas alunas do $2^{\circ}$ Nutrição B: Aurora Yogui, Emília Harada, Estela Maria Tesser, Iderli Eugênio, Ikuyo Araki, Marcia Filimena Rapaci, Márcia Regina Corrêa, Maria Lucélia de Oliveira, Marília Marques da Cruz e Martha Lopes Ribeiro, novembro, 1971. Acervo do Centro de Memória da Escola Técnica Estadual Carlos de Campos, em 2001.

Rev. Iberoam. Patrim. Histórico-Educativo, Campinas (SP), v. 5, p. 1-23, e019012, 2019 
as aulas teóricas, é como se o dispensário não tinha(sic) mais nada a ver com a direção da Carlos de Campos, nem responsabilidade, nem nada, ficou sendo um Posto de Puericultura do Estado [...].

Em 15 de janeiro de 2002, a prof ${ }^{a}$ Neide Gaudenci de Sá, que se formou em Economia Doméstica e Auxiliar de Alimentação, conta no seu depoimento sobre as práticas escolares em 1950, naquele Dispensário, quando esta cursava a cadeira de Puericultura, naquele curso:

[...] Como prova de habilitação no final de curso, muitas vezes era alimentação infantil e então a gente utilizava o dispensário. E ali a gente tinha a oportunidade de assistir as consultas e eram importantíssimas, porque naquele momento, os doutores, que eram nossos professores de puericultura, explicavam muita coisa com a criança ali e então era muito fácil da gente entender, e a gente inclusive acompanhava, porque nós ficávamos três a quatro meses estagiando e a gente via essa criança voltando já com a situação dela resolvida, ou não, e eu assisti muita coisa. Um dia eu vi uma coisa que eu gostaria até de registrar: apareceu para consulta um nenezinho no colo da avô e com o pai, a mãe tinha falecido no parto, coisa que ocorria bastante naquela época. E aí o Dr. Mário perguntou: - como vai ser o nome da menininha? E o pai falou, vai ser Póstuma, porque ela nasceu depois que a mãe morreu. E eu assisti o Dr. Mário dar uma aula para esse pai, impedindo que a criança tivesse esse nome, porque ela iria lembrar a vida inteira que a mãe tinha morrido quando ela tinha nascido. Isso para mim foi uma lição muito importante também. E tudo o que aprendi naquele dispensário. Ele não tinha registrado felizmente O Dr. Mário dizia põe Maria, ficou bravo, muito bravo. Põe o nome da avó. [...].

Naquele depoimento, a Prof ${ }^{a}$ Neide Gaudenci de Sá, como professora de nutrição daquela escola, informou que continuou utilizando-se das práticas escolares desenvolvidas naquele Dispensário, coletando dados sobre as curvas ponderais, que eram obtidas a partir das pesagens mensais das crianças que freqüentavam aquele estabelecimento. Ao ser questionada sobre a polêmica gerada, na década de 1950, entre o Dr. Grechi e o Dr. Taddeo, sobre o emprego de farinha nas preparações das mamadeiras, esta professora comentou que:

[...] O Dr. Greche e o Dr. Taddeo não tinham as mesmas opiniões de alimentação de bebê. O Dr. Greche é muito especial, fez um trabalho sobre o excesso de hidrato de carbono industrializado, ele acha que todas as doenças das crianças: otite, faringite, amidalite, é por excesso de hidrato de carbono industrializado. Ele falava, bate o leite com banana e o açúcar da banana está bom. Mas que mãe que vai dar leite com banana para bebê, é meio difícil. Mas, quando ele foi médico no SESI ele conseguiu um grupo de mães que fizeram a dieta dele, só que é cara a dieta, como não tem hidrato de carbono você tem que dar proteína para a criança, queijo em grande quantidade, porque senão a criança volta e pede comida de novo. Enquanto você dá uma bolacha e acabou. Só mães com poder aquisitivo melhor [...].

Nos anais do II Congresso Brasileiro de Nutricionistas, em São Paulo, encontra-se o trabalho "Plano de alimentação infantil em São Paulo", que o Dr. Henrique Grechi ${ }^{13}$ apresentou

\footnotetext{
${ }^{13}$ Os textos normativos devem sempre nos reenviar às práticas; mais que nos tempos de calmaria, é nos tempos de crise e de conflitos que podemos captar melhor o funcionamento real das finalidades atribuídas à escola (JULIA, 2001, p.19).
} 
referente ao uso indiscriminado de hidratos de carbonos refinados (açúcar e farinha branca) ingeridos pelas crianças (GRECHI, 1960).

O Dispensário de Puericultura continuou sendo administrado pelo Dr. Mario Taddeo até a década de 70, quando ocorreu o encerramento de suas atividades. Em 1970, Sirlei Lopes Simões, mãe da prof ${ }^{a}$ Ligia Simões Baptista que é nutricionista e ministra aulas no curso Técnico de Nutrição da Escola Técnica Estadual Carlos de Campos, a trazia para consultas naquele Dispensário. A Figura 3 mostra o cartão de matrícula $n^{\circ} 4209$ daquela professora; enquanto que a Figura 4 apresenta uma fotografia da professora que, na época, tinha somente três meses de idade. $\mathrm{O}$ verso daquele cartão de matrícula no Dispensário mostra a assinatura do Dr. Mario Taddeo (CARVALHO; RIDOLFI, 2002).

A Figura 5 apresenta a Prof ${ }^{a}$ Ligia Simões Baptista, juntamente com a sua mãe, no Centro de Memória daquela escola, quando esta deu um depoimento, em 18 de janeiro de 2002, sobre as práticas escolares naquele Dispensário de Puericultura.

Sirlei Lopes Simões era usuária daquele Dispensário de Puericultura, desde 1967, quando trazia a irmã mais velha de Lígia. Quando questionada sobre o tratamento que as suas filhas recebiam neste estabelecimento, esta nos informou que: 
Figura 3 - Cartão de matrícula n 4209 de Lígia Lopes Simões, no Dispensário de Puericultura da Escola Industrial Carlos de Campos. Serviço de Saúde Escolar, atendida pelo médico Dr. Mario Taddeo, 1970.
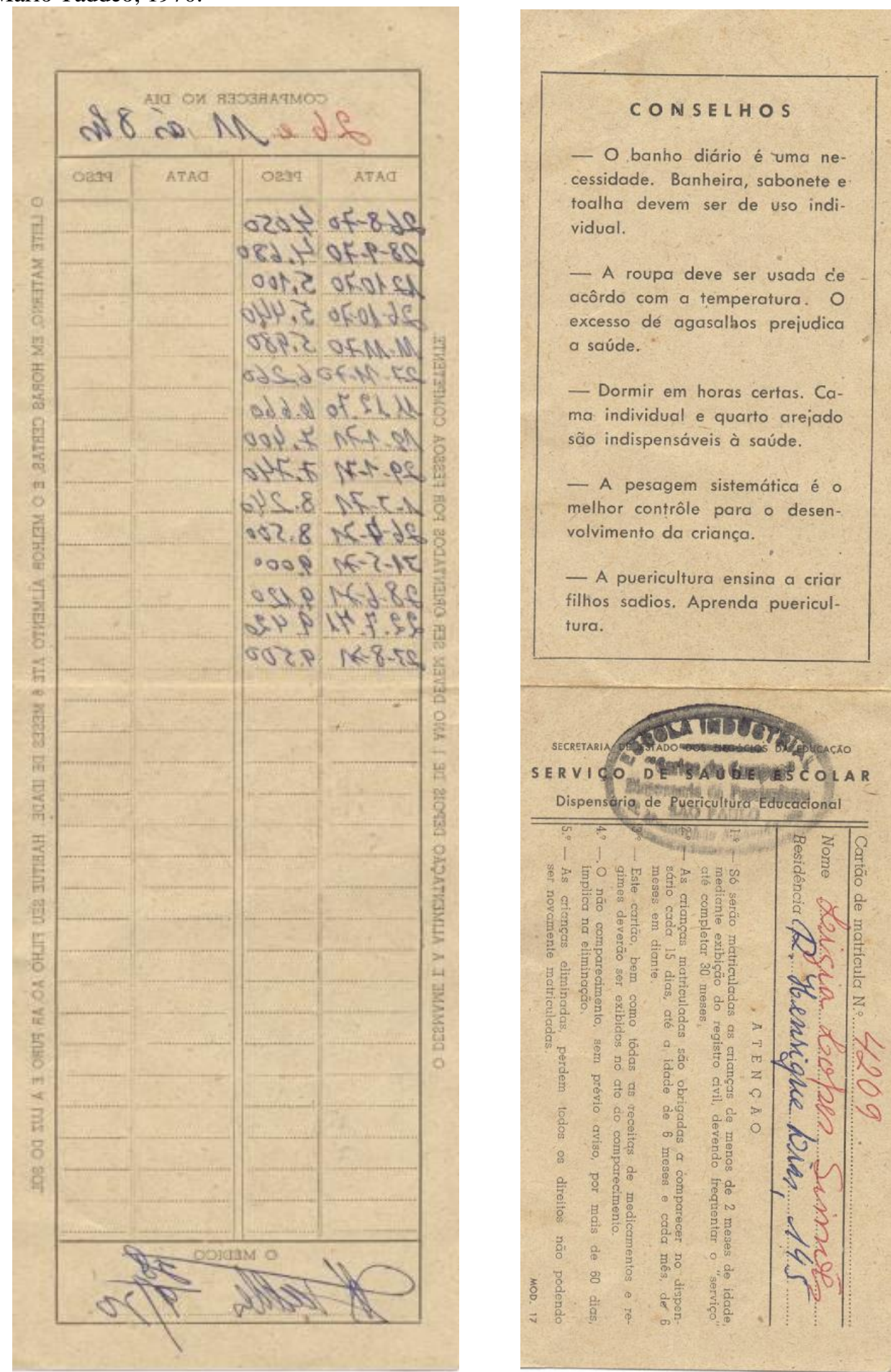

Fonte: Imagem digital em arquivo próprio em 2018. 
Figura 4 - Lígia Simões Baptista, com três meses de idade, usuária do Dispensário de Puericultura no Colégio de Economia Doméstica e Artes Aplicadas Estadual “Carlos de Campos”, 1970.

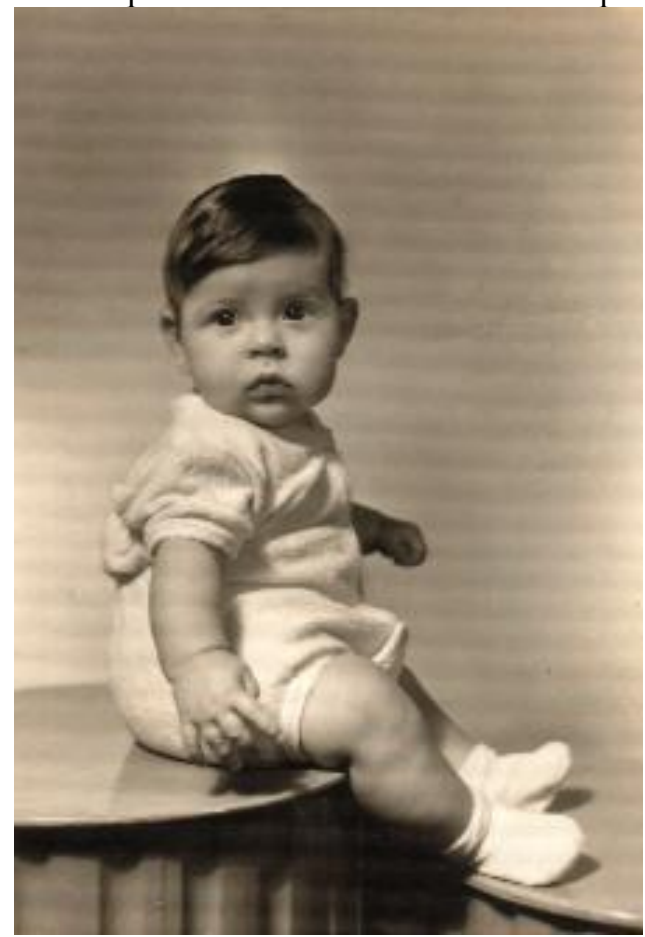

Fonte: Imagem digital em arquivo próprio, em 2018.

Figura 5 - Lígia Simões Baptista, professora do curso Técnico em Nutrição e Dietética da ETE Carlos de Campos, que foi usuária do Dispensário de Puericultura, em 1970, com a sua mãe Sirlei Lopes Simões, 2002.

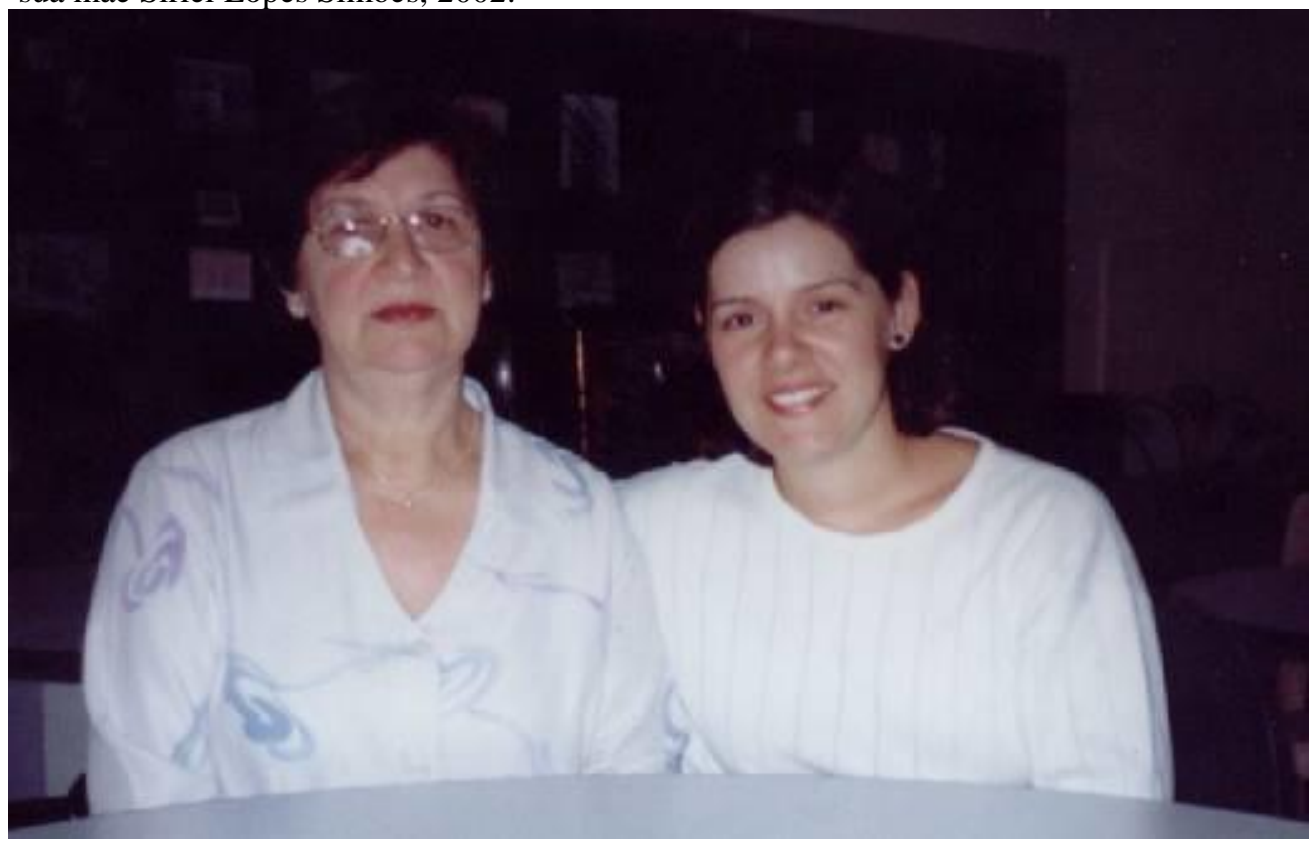

Fonte: Imagem digital em arquivo próprio, em 2018.

[...] Eu gostava muito. Eles eram um atendimento muito bom, excelente, principalmente pela época. Além do que, eles tratavam profissionalmente, eles tinham um vínculo de carinho, de amizade. O Dr. Mario Taddeo, ele era exigente, ele exigia mesmo, que cumprisse as ordens dele. Pergunta: As alunas presenciavam as consultas das crianças? Resposta: algumas vezes, nem sempre, eu acho que dependia das aulas

Rev. Iberoam. Patrim. Histórico-Educativo, Campinas (SP), v. 5, p. 1-23, e019012, 2019 
que elas tinham; às vezes uma turma vinha e assistiam. Aconteceu de elas virem e acompanharem todo o procedimento.

O Colégio Técnico Estadual Carlos de Campos, denominação daquela escola, em 1975, era a única escola que oferecia o curso Técnico em Nutrição e Dietética, em São Paulo, formando em média 70 alunos por ano. Naquela época, era ministrada a disciplina "Puericultura e Dietética Infantil" pelo Dr. Henrique Grechi (CARVALHO, 2006). Para as práticas escolares, este médico empregava como material didático, o "Manual de Puericultura Infantil", de sua autoria. A Figura 6 mostra aquele professor ministrando aulas práticas em sala de aula às alunas do referido curso. Em seu depoimento, em dezembro de 2001, o Dr. Grechi contou-nos que:

[...] As alunas, eu pedia a elas que trouxessem uma criança da família delas, ou conhecida, naquela faixa de idade, quatro meses de idade. Então eu passava a mostrar para as alunas, todas, o que era uma criança de quatro meses. Mostrava todos os caracteres, os progressos e as dificuldades, aquela parte psíquica da criança e também estudava com a mãe da criança a alimentação que ela estava recebendo. Nós tínhamos condições de pesar a criança lá, depois nós dávamos as orientações baseadas nas aulas teóricas que eu tinha ensinado [...].

Menezes e Pinheiro (2016) informam que para a prática de ensino, na Escola Normal de Campinas era importante a preparação pedagógica com aulas figuradas e ida dos alunos da escola modelo à sala do $4^{\circ}$ ano para ser dada aula por um praticante. Segundo as autoras, no Anuário (1918, p. 289 apud MENEZES; PINHEIRO, 2016, p. 179), “uma prática de ensino de observação viva offerece sempre oportunidades de os professores experimentados e de boa vontade applicarem a critica pedagógica, poderoso elemento de educa ção, cujas vantagens são indiscutíveis".

Para continuar investigando o ensino da puericultura, naquele Dispensário, decidimos restringir o corpus do estudo e analisar aqueles dois livros, o "Os Cursos de Dietética", livro institucional ${ }^{14}$, e "Manual de Puericultura e Dietética Infantil", livro didático, considerando-os como fonte de pesquisa em História da Educação, por fazerem parte da cultura escolar e por serem considerados instrumentos de aprendizagem no ensino de puericultura. Segundo Vidal (2005, p. 23), "há aproximadamente 10 anos, a categoria cultura escolar vem subsidiando as análises historiográficas e assumindo visibilidade na estruturação de eventos no campo da História da Educação". Aqueles livros, Figuras 7 e 8, foram empregados nas práticas

\footnotetext{
${ }^{14}$ Silvina Gvirtz diz que quando se trata de realizar uma abordagem da escola em tempos passados, se dificulta o acesso ao ensinado e maior peso adquirem aquelas fontes que se referem ao normativo e ao pedagógico (planos, programas, revistas especializadas, etc.), sendo necessário muitas vezes inferir delas o ensinado, com todas as dificuldades que acarreta (GVIRTZ, 2005, p. 22).
} 
pedagógicas e nas práticas escolares, naquela escola, em diferentes períodos. Para esta análise consideraremos o espaço, o tempo e a subjetividade dos integrantes daquele Dispensário.

Figura 6 - Alunas do curso de Nutrição e Dietética, na disciplina de Puericultura, em sala de aula, recebendo instruções do professor Dr. Henrique Grechi sobre a técnica de pesagem dos nenês, na Escola Técnica de $2^{\circ}$ Grau Carlos de Campos, atual ETE Carlos de Campos.

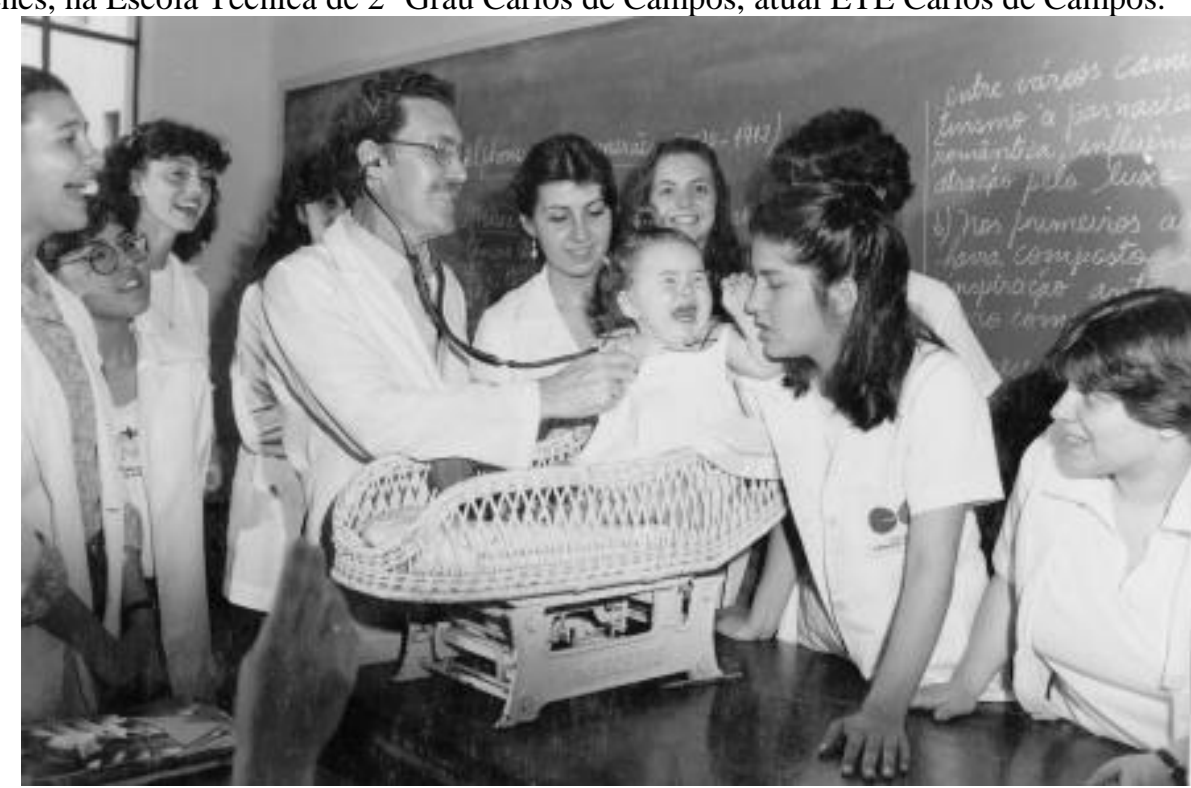

Fonte: Acervo do Centro de Memória da Escola Técnica Estadual Carlos de Campos, em 2001.

Figura 7 - Livro Institucional “Os Cursos de Dietética” (SÃO PAULO, 1939).

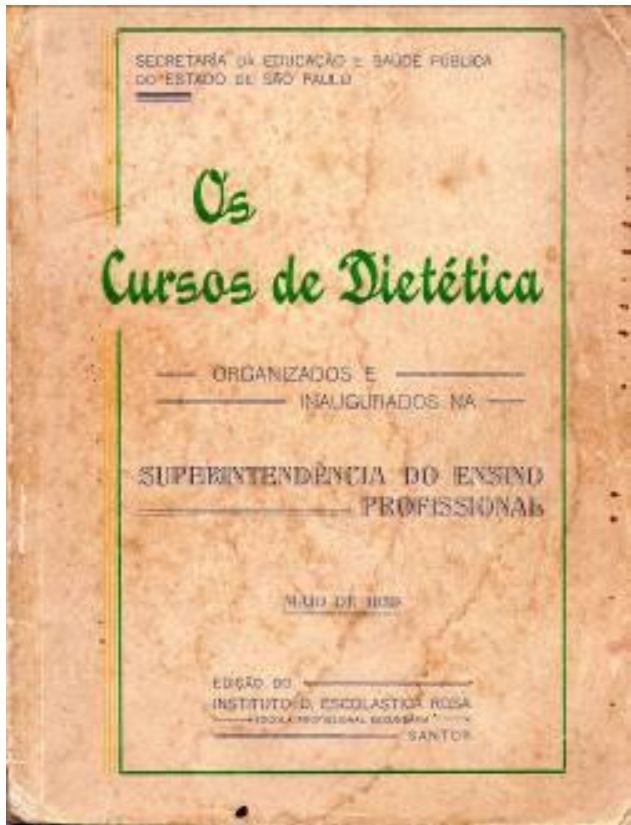

Fonte: Acervo do Centro de Memória da Escola Técnica Estadual Carlos de Campos, em 2001. 
Figura 8 - Livro didático. Manual de Puericultura e Dietética Infantil. Cadeira de Puericultura e Dietética de autoria do Dr. Henrique Grechi, professor do Centro Estadual Interescolar "Carlos de Campos", década de 70 .

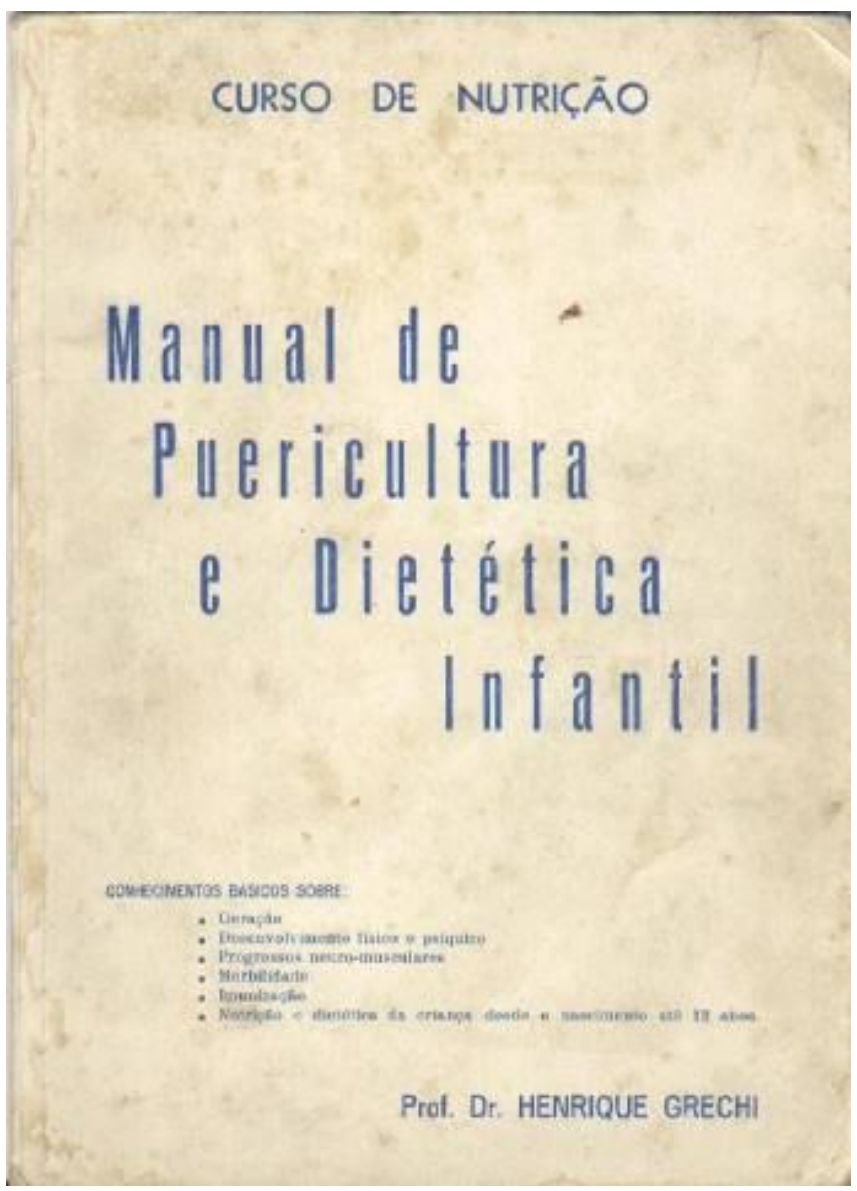

Fonte: Acervo do Centro de Memória da Escola Estadual Carlos de Campos, em 2001.

Nesta investigação as práticas foram consideradas relevantes para a historicidade daquele Dispensário de Puericultura, portanto, assumindo uma perspectiva foucaultiana ${ }^{15}$, decidimos empregar como referencial teórico às definições de Gvirtz (2005), para as práticas discursivas:

A referência práticas discursivas escolares é explicitamente mencionada para diferenciá-la de outro tipo de práticas discursivas que aqui são chamadas de práticas discursivas pedagógicas. As primeiras se distinguem destas últimas à medida que se considera que são produção da escola e as segundas seriam produções sobre a escola, e que conformariam metadiscursividades como práticas discursivas (as pedagógicas) referidas a outras práticas discursivas.

\footnotetext{
${ }^{15}$ Veiga-Neto (2003, p. 54), informa que "pela palavra prática [Foucault] não pretende significar a atividade de um sujeito, [mas] designa a existência objetiva e material de certas regras a que o sujeito está submetido desde o momento em que pratica o - discurso - Os efeitos dessa submissão do sujeito são analisados sob o título: posições do sujeito (LECOURT, 1980, p. 91)".
} 


\title{
O LIVRO INSTITUCIONAL COMO FONTE DE PESQUISA PARA ELUCIDAR AS PRÁTICAS PEDAGÓGICAS
}

A Superintendência do Ensino Profissional apresentou os Cursos de Dietética, ao Dr. Álvaro de Figueiredo Guião, Secretário da Educação e Saúde Pública do Estado de São Paulo, ao propor-lhe a criação dos mesmos, em 1939, dizendo que ${ }^{16}$ :

\begin{abstract}
$\mathrm{Na}$ campanha que ora se inaugura e que possue uma alevantada finalidade patriótica, cabe plenamente ás Escolas Profissionais um papel saliente. Como mantêm cursos de economia domestica, de puericultura e de diversas atividades técnicas especializadas, esses estabelecimentos podem e devem lançar, em nosso país, os primeiros cursos profissionais de dietética. Sentem-se habilitados a criar mais essa profissão, indispensável para que se processe, entre nós, a divulgação prática dos ensinamentos que conduzirão ao almejado fim.
\end{abstract}

Para justificar a publicação daquele livro institucional, a Superintendência do Ensino Profissional, informou na apresentação do mesmo, que por tratar-se de cursos novos, inexistentes no país, muitos terão interesse em conhecer os decretos que organizaram os cursos de dietética, os programas das diversas cadeiras que compõem aqueles cursos: "Curso de Dietética, para Donas de Casa" e "Curso de Auxiliares em Alimentação", inclusive a maneira pela qual foram estas cadeiras enquadradas entre as pré-existentes nos cursos técnicos especializados e o próprio desenvolvimento do ensino, ou seja, as práticas pedagógicas (SÃO PAULO, 1939).

Na capa daquele livro institucional constam descritos: Secretaria da Educação e Saúde Pública do Estado de São Paulo, no cabeçalho; no meio da capa o título da publicação "Os Cursos de Dietética", citando ter sido "organizados e inaugurados na Superintendência do Ensino Profissional", maio de 1939, e o nome da editora, "Edição do Instituto D. Escolástica Rosa - Escola Profissional Secundária - Santos". A publicação tem capa dura, nas dimensões de $15,5 \mathrm{~cm}$ x 20,5 cm, sem numeração de páginas. Aquela publicação pertenceu a Isabel Marcondes Machado e encontra-se no acervo do Centro de Memória da Escola Técnica Estadual Carlos de Campos.

Aquela publicação traz os planos elaborados para aulas teóricas e prática da cadeira de Puericultura. Podemos considerar aqueles planos, como práticas pedagógicas elaboradas para

\footnotetext{
${ }^{16}$ Schwartzman, Bomeny e Costa (2006) citam a posição do Ministério da Educação, no governo de Getúlio Vargas, quanto à escolarização das mulheres: "O tratamento especial que Capanema reserva às mulheres se desdobraria em dois planos. Por um lado, haveria que proteger a família; por outro, haveria que dar à mulher uma educação adequada ao seu papel familiar".
} 
disseminar conhecimentos de forma uniforme entre os Dispensários de Puericultura das escolas profissionais no estado de São Paulo. Segundo Azanha (1991, p. 65):

\begin{abstract}
Um mínimo de reflexão nos lembrará que, historicamente, o aparecimento de escolas representou a institucionalização de práticas que, pela sua crescente complexidade, exigiam a liberação parcial das famílias do esforço educativo. Esta transferência de responsabilidades foi um processo muito complexo e envolveu, em cada sociedade e em cada momento histórico, as cambiantes e problemáticas relações entre o público e o privado. Nesse quadro, não é obvio que a interpenetração máxima entre escola e comunidade seja indiscutivelmente um benefício para a educação das crianças.
\end{abstract}

Constam também naquela publicação, os programas do curso de "Educação doméstica e dietética para donas de casa e do curso de Auxiliares em alimentação", para alunas do curso de aperfeiçoamento que se candidatarem ao exercício da profissão. Aqueles programas descrevem para cada cadeira pertencente aos cursos, os conteúdos teórico e prático. Os quadros I e II apresentam os conteúdos que devem ser desenvolvidos na cadeira de Puericultura para aqueles cursos. Segundo Julia (2001, p. 17), "pode-se tentar reconstituir, indiretamente, as práticas escolares a partir das normas ditadas nos programas oficiais ou nos artigos das revistas pedagógicas”.

\title{
O LIVRO DIDÁtico COMO FONTE de PESQUiSAS PARA ELUCIDAR AS PRÁTICAS ESCOLARES
}

O livro didático 17 "Manual de Puericultura e Dietética Infantil""18 - Curso de Nutrição, de autoria do Prof. Dr. Henrique Grechi, responsável por este componente curricular, naquela escola, apresenta na capa os tópicos dos conhecimentos básicos sobre: geração, desenvolvimento físico e psíquico, progressos neuro-musculares, morbilidade, imunização,

\footnotetext{
${ }^{17}$ Os livros escolares, de modo geral, configuram um objeto em circulação - como bem frisa Chartier (1990) - e, por essa razão, são veículos de circulação de idéias que traduzem valores, como já dissemos, e comportamentos que se desejou fossem ensinados. Some-se a isso o fato de que a relação entre livro escolar e escolarização permitem pensar na possibilidade de uma aproximação maior do ponto de vista histórico acerca da circulação de idéias sobre o que a escola deveria transmitir/ensinar e, ao mesmo tempo, saber qual concepção educativa estaria permeando a proposta de formação dos sujeitos escolares. Nesse sentido, então, esse tipo de fonte pode servir como um indicador de projeto de formação social desencadeado pela escola. Isso é permitido por meio das interrogações que podem ser feitas, quer em termos do conteúdo, quer de discurso, sem deixar de levar em consideração aspectos referentes a temporalidade e espaço. O que, por sua vez, possibilita indagar sobre a que e a quem serviu como um dos instrumentos da prática institucional escolar. Nesse aspecto, em particular, vincula-se à história das instituições escolares e, amplamente, à das políticas educacionais ( CORRÊA, 2000)

${ }^{18}$ O Dr. Henrique Grechi, na apresentação daquele Manual, define que: "Puericultura e Dietética Infantil são conhecimentos correlatos. Na Puericultura objetiva-se a formação completa da criança, isto é o seu desenvolvimento normal, físico e psíquico e a proteção contra agentes infecciosos, climáticos e traumas que podem lesar o seu organismo. Na Dietética Infantil estudam-se todas as peculiaridades alimentares que garantem uma nutrição normal e perfeita da criança. Ora, sem uma nutrição perfeita não haverá nem desenvolvimento, nem saúde. A criança adoece pela desnutrição e morre pela infecção".
} 
nutrição e dietética da criança desde o nascimento até 12 anos, de que se trata neste livro didático. Este manual tem o formato de um caderno, $16 \mathrm{~cm}$ x 22,5 cm, com capa dura, composto de 64 páginas, e na última página, constam as seguintes informações: "Para maiores esclarecimentos deste manual procurar seu autor: Dr. Henrique Grechi, Rua Siqueira Bueno, 57 - Tel.: 92-4359, São Paulo”. Sabe-se que esse é o endereço do autor. Em dezembro de 2001, entrevistamos o Prof. Dr. Henrique Grechi ${ }^{19}$, em sua residência, logo na entrada da casa térrea, na varanda, do lado esquerdo ficava o consultório daquele médico pediatra, que embora não estivesse mais clinicando, mantinha nele documentos de sua profissão. Aquele manual pertenceu à aluna Eliana Mardirossian, naquele consta que estava no $3^{\circ} \mathrm{M}$, da Carlos de Campos, supõe-se que aquele dado refere-se ao terceiro ano da manhã. O quadro III apresenta os tópicos tratados naquele Manual de Puericultura e Dietética Infantil.

\section{CONSIDERAÇÕES FINAIS}

Os livros institucional e didático - "Os Cursos de Dietistas" e "Manual de Puericultura e Dietética Infantil" - foram utilizados neste artigo para compreender por meio deste instrumento de ensino-aprendizagem as práticas pedagógicas e as práticas escolares empregadas na disciplina de Puericultura no período de existência do Dispensário de Puericultura da primeira Escola Profissional Feminina. Estes livros localizados no Centro de Memória daquela escola foram considerados como fonte de pesquisa em História da Educação, por fazer parte da cultura escolar e por serem considerados como "possuidor de valores que se desejou fossem transmitidos num dado momento histórico, ao mesmo tempo em que é portador de um projeto de nação a ser construído por meio da educação escolar" (CORRÊA, 2000). Os resultados parciais obtidos com a análise dos dados coletados naquele acervo permitiram identificar como as meninas e as adolescentes foram forjadas a disciplinarem as suas "palavras, intenções e gestos" ${ }^{20}$, tornando-se "sujeitos civilizados" para procriarem e para preservarem a própria vida e de suas famílias.

\footnotetext{
${ }^{19}$ O autor é diplomado em 1948 pela Faculdade de Medicina da Universidade de São Paulo. Especialista em Pediatria desde 1950. Duplamente concursado no magistério público, nas cadeiras de Puericultura (C.T. $2^{\circ}$ Grau Carlos de Campos) e Biologia (CE Prof. Ascendino Reis), Capital. Médico chefe do Serviço Integrado de Assistência ao Escolar do SESI. Autor de livro didático "Economia Doméstica e Puericultura" em parceria com a Profa. Helena Rossi Penna. Edições Melhoramentos, 1954. Membro ativo do II Congresso de Nutricionistas, em São Paulo, com o trabalho "Plano de Alimentação Infantil em São Paulo", 1960 (GRECHI, 1994).

${ }^{20}$ PEREIRA NETO, 1997. Palavras, intenções e gestos. Tese de Doutoramento na Faculdade de Saúde Pública da Universidade Estadual do Rio de Janeiro.
} 


\section{REFERÊNCIAS}

AZANHA, José Mário Pires. Cultura escolar brasileira. Um programa de pesquisas. Revista da Universidade de São Paulo, n. 8, p. 65-69, dez./fev. 1990-1991.

BARDIN, Laurence. Análise de Conteúdo. 3. ed. Lisboa: Edições 70, LDA, 2004.

CARVALHO, Maria Lucia Mendes; FERREIRA, Eliana Roda. Entrevista com a ex-professora Neide Gaudenci de Sá, no Centro de Memória da Escola Técnica Estadual Carlos de Campos, 26 de dezembro de 2001. In: CARVALHO, Maria Lucia Mendes de Carvalho. Historiografia das Escolas Técnicas mais Antigas do Estado de São Paulo. Relatório de Atividades Desenvolvidas no Centro Paula Souza para o Projeto da Fundação de Apoio a Pesquisa do Estado de São Paulo, janeiro a outubro, 2002.

CARVALHO, Maria Lucia Mendes; RIDOLFI, Deborah de Marco. Relatório de visita à exprofessora Íris Krauss, 03 de janeiro de 2002. In: CARVALHO, Maria Lucia Mendes de Carvalho. Historiografia das Escolas Técnicas mais Antigas do Estado de São Paulo. Relatório de Atividades Desenvolvidas no Centro Paula Souza para o Projeto da Fundação de Apoio a Pesquisa do Estado de São Paulo, janeiro a outubro, 2002.

CARVALHO, Maria Lucia Mendes. História do currículo do Técnico em Nutrição e Dietética: na Escola Técnica Estadual Carlos de Campos, em São Paulo, com ênfase na Puericultura. I JORNADA NACIONAL DA PRODUÇÃO CIENTÍFICA EM EDUCAÇÃO PROFISSIONAL E TECNOLÓGICA. Anais [...]. Ministério da educação, Brasília, mar. 2006.

CARVALHO, Maria Lucia Mendes. Dispensário de Puericultura: Escola Profissional Feminina na Assistência e Proteção à Infância. VI CONGRESSO LUSO-BRASILEIRO DE HISTÓRIA DA EDUCAÇÃO. Anais [...]. Universidade Federal de Uberlândia, abr. 2006.

CASTRO, Maria Antonieta. O Ensino da Puericultura nas Escolas e Agremiações Femininas: tese apresentada à Conferência Nacional de Proteção à Infância, em setembro de 1933. Revista de Educação. São Paulo: Tipografia Garraux, v. IV, dez. 1933.

CERTEAU, Michel. A invenção do cotidiano. Artes de fazer. Petrópolis, RJ: Vozes, 1994.

CORRÊA, Rosa Lydia Teixeira. O livro escolar como fonte de pesquisa em História da Educação. Caderno CERES, v. 20, n. 52, Campinas, 2000. Disponível em: www.scielo.br. Acesso em: 14 mar. 2006.

GRECHI, Henrique. Manual de Puericultura e Dietética Infantil. Curso de Nutrição, São Paulo, s/d.

GRECHI, Henrique. Plano de Alimentação Infantil em São Paulo. II CONGRESSO BRASILEIRO DE NUTRICIONISTAS. Anais [...]. São Paulo, jul. 1960.

GRECHI, Henrique. Manual de manutenção do bebê. Guarulhos, SP: Lis Gráfica e Editora, 1994. 
GVIRTZ, Silvina. Do Currículo Prescrito ao Currículo de Classe: um olhar sobre os cadernos de classe. Bragança Paulista, SP: Editora Universitária São Francisco, 2005.

JULIA, Dominique. A cultura escolar como objeto histórico. Revista Brasileira de História da Educação, n. 01, jan./jun. 2001.

MENEZES, Maria Cristina; PINHEIRO, Maria de Lourdes. Um médico italiano para a escola republicana paulista: a pedagogia científica nas escolas normais brasileiras. Rev. Iberoam. Patrim. Histórico-Educativo, Campinas (SP), v. 2, n. 3, p. 163-181, jul./dez. 2016. Disponível em: https://econtents.bc.unicamp.br/inpec/index.php/ridphe/article/view/9264. Acesso em: 22 dez. 2018.

MORAES, Carmen Sylvia Vidigal. A socialização da força de trabalho: instrução popular e qualificação profissional no Estado de São Paulo (1873 - 1934). Bragança Paulista, SP: Editora da Universidade São Francisco, 2003.

ROCHA, Heloísa Helena Pimenta Rocha. Prescrevendo regras de bem viver: Cultura escolar e racionalidade científica. Cadernos CEDES, v. 20, n. 52, Campinas, nov. 2000. Disponível em: http://www.scielo.br. Acesso em: 2 dez. 2005.

SÃO PAULO (Estado). Secretaria da Educação e Saúde Pública do Estado de São Paulo. Superintendência do Ensino Profissional (org. e inaugurados). Os Cursos de Dietética. Edição do Instituto D. Escolástica Rosa, Escola Profissional Secundária, Santos, maio 1939.

SÃO PAULO (Estado). Secretaria da Educação e Saúde Pública do Estado de São Paulo. Superintendência do Ensino Profissional (org. e inaugurados). Os Cursos de Dietética. Edição do Instituto D. Escolástica Rosa, Escola Profissional Secundária, Santos, maio 1939.

SCHWARTZMAN, Simon; BOMENY, Helena Maria Bousquet; COSTA, Vanda Maria Ribeiro. Contenção de Mulheres, Mobilização dos Jovens. In: SCHWARTZMAN, Simon; BOMENY, Helena Maria Bousquet; COSTA, Vanda Maria Ribeiro. Tempos de Capanema. São Paulo: Editora da Universidade de São Paulo; Paz e Terra, 1984. Disponível em: www.schwartzman.org.br/simon/capanema/capit4.htm. Acesso em: 25 abr. 2006.

SILVEIRA, Horácio Augusto. Escola Normal Feminina de Artes e Ofícios (São Paulo) Histórico e organização atual. $2^{\circ}$ CONGRESSO FEMINISTA. Anais [...]. São Paulo, 1931.

VEIGA-NETO, Alfredo. Foucault \& a Educação. Belo Horizonte, MG: Autêntica, 2003.

VIDAL, Diana Gonçalves. Culturas Escolares: Estudo sobre práticas de leitura e escrita na escola pública primária (Brasil e França, final do século XIX). Campinas, SP: Autores Associados, 2005.

VIÑAO FRAGO, Antonio. Historia de la educación e historia cultural. Posibilidades, problemas, cuestiones. Revista Brasileira de Educação, n. 0, set./dez. 1995. 


\section{Quadro I - Programa do curso de Educação Doméstica e Dietética para Donas de Casa, Cadeira de Puericultura (SÃO PAULO, 1939).}

\section{$2^{\circ}$ Ano Profissional}

1 - A criança. O que ela representa para a sociedade. Seus direitos. Defesa e proteção. Puericultura.

2 - Mortalidade e morbilidade. Dados estatísticos. Suas causas: fatores hereditários, ignorância, miséria, etc. Combate à mortalidade infantil.

3 - Direitos da gestante. Higiene pré-natal.

4 - Primeiros cuidados com o recém-nascido, sobretudo os relativos ao cordão, a cicatriz umbelical, aos olhos e a pele. Técnica do banho. Higiene dos ouvidos, nariz e garganta. Vestuário. Enxoval do recém-nascido. Confeção de peças.

5 - Característicos principais do recém-nascido. Morfologia e fisiologia. Icterícia fisiológica, mecônico, colostro e descamação. Peso e altura. Pesagem sistemática. Curva de peso.

6 - Aleitamento materno e sua importância. Alimentação mercenária. Suas indicações e inconvenientes. Higiene da nutriz. Técnica de alimentação natural. Necessidade de vitaminas.

7 - Alimentação mista. Quando se torna necessária. Alimentos indicados. Técnica.

8 - Alimentação artificial. Alimentos usados em casos normais. Técnica. Higiene de mamadeiras e bicos.

9 - Desmame. Como e quando deve ser processado.

10 - Dentição. Combate as idéias errôneas sobre o assunto.

11 - Hábitos sadios. Asseio corporal, ar livre, sono, exercício e repouso. Posição, alimentação e eliminação de excretas.

12 - Personalidade sadia. Higiene. Perigo de superstições e crendices.

13 - Lar e comunidade sadios. Higiene da habitação. Defesa contra moléstias infeto-contagiosas no meio familiar: tuberculose, lepra e outras.

14 - Moléstias mais comuns na infância. Sua profilaxia. Imunisação.

15 - A criança doente. Cuidados a tomar antes da chegada do médico. A mãe como auxiliar do médico.

\section{$3^{\circ}$ Ano Profissional}

\section{$1^{a}$ parte: TEORIA}

Revisão e desenvolvimento do programa de $2^{\circ}$ ano.

Aprendizagem da escrituração dos Dispensários de Puericultura: fichas, estatísticas, gráficos, etc.

$2^{\mathrm{a}}$ parte: COZINHA DIETÉTICA

1 - Reconhecimento das farinhas e produtos caseinados.

2 - Leites em pó. Seu preparo simples ou com adição.

3 - Preparo de mingaus simples.

4 - Açucares nutritivos. Seu preparo.

5 - Leite albuminoso. Seu preparo $\left(1^{\circ}\right.$ e $2^{\circ}$ processos $)$

6 - Leitelho natural. Seu preparo. Dosagem do leitelho.

7 - Leitelho em pó. Seu preparo.

8 - Leite acidificado. Seu preparo.

9 - Leites caseinados. Seu preparo.

10 - Decotos e mucilagens. Seu preparo.

11 - Butiro farinácio. Seu preparo

12 - Sopa maltada de Killer. Seu preparo.

13 - Sôpas de legumes. Pastilhas. Seu preparo.

14 - Leite de amêndoas. Seu preparo.

15 - Pirão de legumes, batatas, pêras e maçãs.

16 - Caldo de frutas. Geléia de laranjas. Omelete de bananas. 


\section{Quadro II - PROGRAMA DO CURSO DE “AUXILIARES EM ALIMENTAÇÃO”, PARA ALUNAS DO CURSO DE APERFEIÇOAMENTO QUE SE CANDITAREM AO EXERCÍCIO DA PROFISSÃO, CADEIRA DE PUERICULTURA.(SÃO PAULO,1939).}

\footnotetext{
$1^{\circ}$ e $2^{\circ}$ Anos - Curso Teórico e Prático

1 - A criança. Seus direitos naturais dentro da sociedade. Meios de proteção ou defesa. Noções de eugenia.

2 - Principais fatores de degenerescência humana: álcool, sífilis, tuberculose, consaguinidade. Exame pré-nupcial.

3 - Causas da morbilidade e mortalidade infantis e sua profilaxia.

4 - Higiene da gestante. Cuidados a serem observados. Assistência pré-natal.

5 - Condições fisiológicas do recém-nascido; mecônio, colostro, descamação, icterícia fisiológica.

6 - Os primeiros cuidados com o recém-nascido, desde o nascimento até a queda do cordão e cicatrização completa da ferida umbilical.

7 - Desenvolvimento ponderal e estatural da criança, nos primeiros meses e o benefício da pesagem sistemática.

8 - As afeções banais e graves dos primeiros dias de vida. Meios de evita-las.

9 - Aleitação natural, materna e mercenária. Os perigos que oferece com esta última, admitida sem escrúpulos. Higiene da nutriz.

10 - Obstáculos na amamentação; multiplicidade de fatores que impedem o aleitamento natural.

11 - Aleitação mista e artificial. A escolha do alimento. Produtos derivados do leite. Mamadeiras e bicos.

12 - Desmame; quando e porque deve ser começado. Causas que determinam o desmame precoce. Necessidade de vitaminas.

13- Noções elementares sobre vitaminas. Substâncias que as contem. Sua importância no organismo. Escorbuto e raquitismo.

14 - Moléstias mais comuns na primeira infância. Necessidade do conhecimento das moléstias eruptivas e cuidados de isolamento, antes da chegada do médico.

15 - Imunidade transmitida. Noções de imunização: B, C. G., anatoxina diftérica, vacina antivariólica e anti-tífica. Necessidade de conhecer o tratamento de certas moléstias da infância, principalmente as moléstias eruptivas e as afeções das vias urinárias.

16 - Necessidade de corrigir dois conceitos errôneos e altamente divulgados entre os leigos: diarréia produzida

pela erupção dos dentes e 'ataque de bichas' . A verdade sobre o assunto.

17 - O banho como sedativo e anti-têrmico. O perigo e o inconveniente dos purgantes, clisteres e lavagens intestinais.

18 - Educação física da criança. Necessidade de ar, luz, e sol. Asseio corporal e higiene em geral.

$2^{\mathrm{a}}$ parte:

a) - Observação no Dispensário de Puericultura do Instituto Profissional Feminino e nos Hospitais Infantis.

b) - Desenvolvimento da parte da escrituração.
} 


\section{Quadro III - Tópicos tratados no Manual de Puericultura e Dietética Infantil, do Prof.} Dr. Henrique Grechi (GRECHI, s/d).

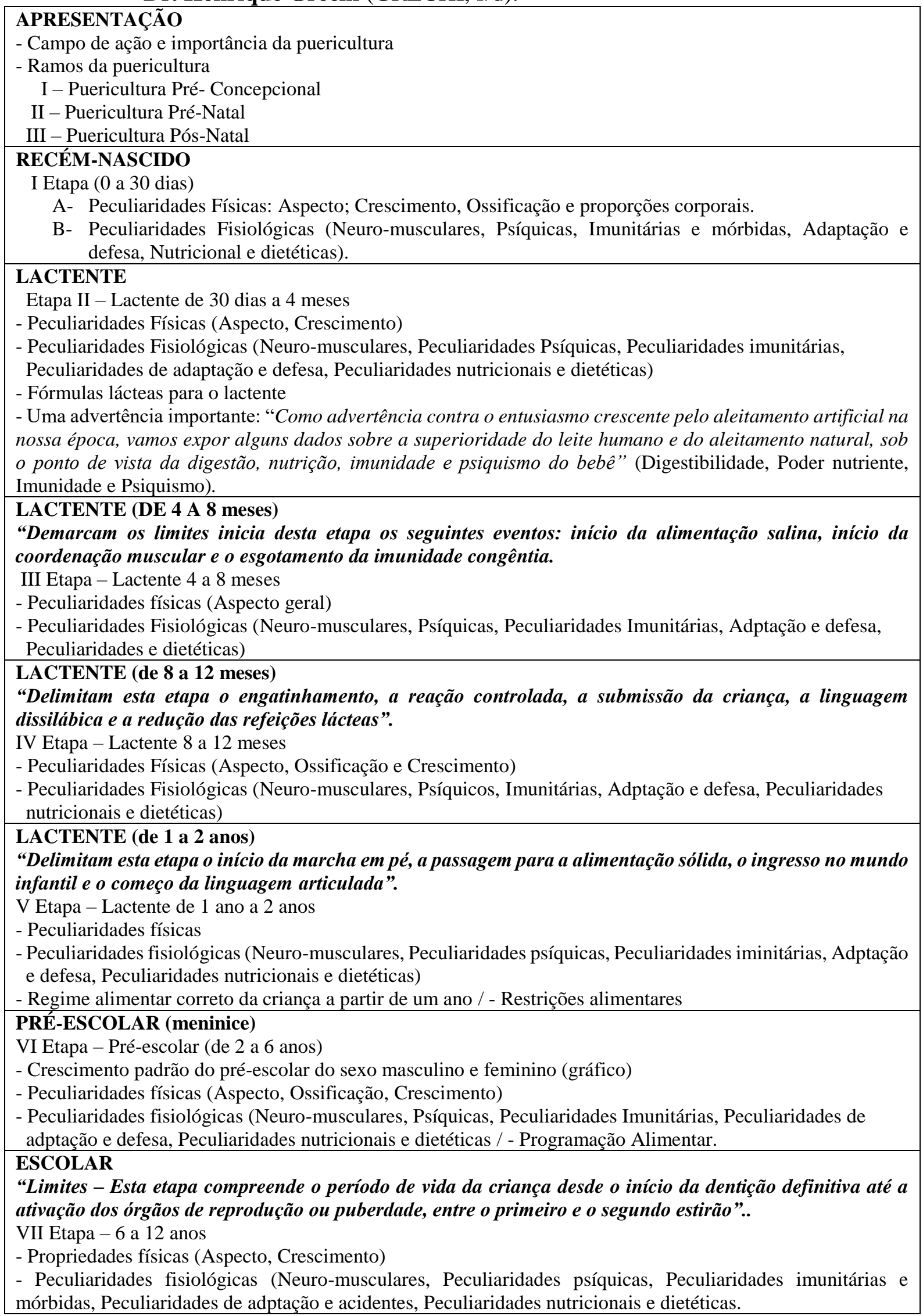

